\title{
Modulating Effect of Ferulic Acid on NF-אB, COX-2 and VEGF Expression Pattern During 7, 12-Dimethylbenz(a)anthracene Induced Oral Carcinogenesis
}

\author{
Shanmugam Manoharan ${ }^{1}, *$, Tharmaraj Rejitharaji ${ }^{1}$, Murugaraj M. Prabhakar ${ }^{1}$. Asokan Manimaran ${ }^{1}$, \\ and Ram B. Singh ${ }^{2}$
}

\author{
${ }^{1}$ Department of Biochemistry and Biotechnology, Annamalai University, Annamalainagar, Tamilnadu, India \\ ${ }^{2}$ Halberg Hospital and Research Institute, Civil Lines, Moradabad-10(UP) 244001, India
}

\begin{abstract}
Ferulic acid, a natural antioxidant, has the potential to prevent inflammation and to modulate angiogenesis in both in vivo and in vitro models. The present study has investigated the modulating effect of ferulic acid on the expression pattern of COX-2, NF- $\mathrm{BB}$ and VEGF during 7,12-dimethylbenz(a)anthracene (DMBA) induced hamster buccal pouch carcinogenesis. Over expression of COX-2, NF- $\kappa \mathrm{B}$ and VEGF was noticed in the oral tumor tissues of hamsters treated with DMBA. Oral administration of ferulic acid at a dose of $40 \mathrm{mg} / \mathrm{kg}$ body weight to hamsters treated with DMBA completely prevented the tumor formation and downregulated the expression of COX-2, NF- $\kappa \mathrm{B}$ and VEGF during DMBA induced oral carcinogenesis. The present results suggest that ferulic acid might have suppressed oral tumor formation by down regulating the expression of COX-2, NF- $\mathrm{KB}$ and VEGF during DMBA induced oral carcinogenesis.
\end{abstract}

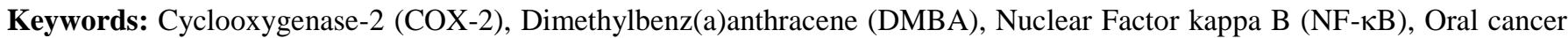
and Vascular Endothelial Growth Factor (VEGF).

\section{INTRODUCTION}

Oral carcinoma, a malignant cancer with poor prognosis and clinical outcome, is the fifth most frequent cancer worldwide. Though the oral cancer incidence is increasing worldwide highest incidences are reported every year from developing countries especially from India, where these forms of cancers account for $40-50 \%$ of all cancer [1]. Extensive use of tobacco, betel quid and alcohol consumption are recognized as major risk factors associated with the pathogenesis of oral cancers in high prevalence areas [2]. Late diagnosis and treatment delay are responsible for poor survival rate of oral cancer patients and the five year survival rate is thus still at 50\% [3]. Oral cancer arises due to accumulation of multiple genetic abnormalities and the molecules that play a critical role in cell proliferation, inflammation and angiogenesis [4].

While cyclooxygenases play a vital role in the inflammatory process and cyclooxygenase-2 (COX-2) has been concerned in the progression of carcinogenesis and angiogenesis. The activity of COX-2 is provoked by tumor promoters, growth factors and cytokines during inflammatory and carcinogenic processes $[5,6]$. NF- $\mathrm{NB}$ plays a key role in the regulation of tumor survival and progression, probably mediating inflammatory process.

*Address correspondence to this author at the Department of Biochemistry and Biotechnology, Faculty of Science, Annamalai University, Annamalainagar, Tamil Nadu - 608002, India; Tel: +914144 239141; Fax: +914144238080; E-mail: sakshiman@ rediffmail.com
$\mathrm{NF}-\kappa \mathrm{B}$ activity is turned on by numerous stimuli which include physical and chemical stresses, viral proteins chemotherapeutic agents and ionizing radiation. It has been reported that activated $\mathrm{NF}-\kappa \mathrm{B}$ is involved in the transcriptional regulation of over 400 genes implicated in inflammation carcinogenesis and cell survival [7]. Over expression of $\mathrm{NF}-\kappa \mathrm{B}$ and $\mathrm{COX}-2$ was reported in several tumors including oral cancer [8-10].

Angiogenesis, the formation of new blood vessels from pre-existing capillaries, has been documented as a fundamental aspect in tumor growth and progression [11]. VEGF, a critical angiogenic factor, perform significant role in increasing vessel permeability and enhancing endothelial cell growth, proliferation, migration, and differentiation [12]. Over expression of VEGF has been reported in several malignancies including oral carcinoma [13-16]. VEGF is thus considered and utilized as a therapeutic target for various cancers including oral cancer [17].

Ferulic acid (4-hydroxy-3-methoxy cinnamic acid), a phenolic compound is present in large quantities in various fruits and vegetables [18]. Ferulic acid possesses a wide range of therapeutic potential, which include antioxidant, anti-inflammatory, antiaging, neuroprotective, hepatoprotective and anticarcinogenic effects $[19,20]$. Balakrishnan et al. (2007) have shown the antigenotoxic effect of ferulic acid in 7-12-dimethylbenz(a)anthracene induced genotoxicity has been reported [21]. Alias et al. reported the protective effect of ferulic acid on DMBA induced skin carcinogenesis in swiss albino mice [22]. 
Previous studies from our laboratory have also shown the chemopreventive potential of ferulic acid against oral and mammary carcinogenesis $[23,24]$. Recently we have shown the proapoptotic and anti-cell proliferative efficacy of ferulic acid against DMBA induced hamster buccal pouch carcinogenesis $[25,26]$. The present study explores the anticell proliferative efficacy of ferulic acid against 7, 12dimethylbenz(a)anthracene inducing hamsters buccal pouch carcinogenesis.

\section{ANIMALS}

Male golden Syrian hamsters, eight weeks old, weighing 80-120g (information provided by the breeder) were purchased from National Institute of Nutrition, Hyderabad and housed in polypropylene cages at room temperature $\left(27 \pm 2^{\circ} \mathrm{C}\right)$ with relative humidity $55 \pm 5 \%$, in the Central Animal House, Annamalai University. The animals were provided with standard pellet diet and water ad libitum. Annamalai University Animal Ethical Committee (Register number 160/1999/CPCSEA), Annamalainagar, India approved the experimental design (proposed no.872, dated 29.05.2012).

\section{TUMOR INDUCTION}

Topical application of $0.5 \%$ DMBA in liquid paraffin three times a week for 14 weeks developed oral squamous cell carcinoma in the buccal pouch of golden Syrian hamsters.

\section{EXPERIMENTAL DESIGN}

Forty golden Syrian hamsters were categorized into four groups of ten hamsters in each. The experimental hamsters were allowed to acclimatize the new environment for about one week before the experimental work was started. Group I hamsters served as control and were painted with liquid paraffin alone three times a week for 14 weeks on their left buccal pouches. Groups II and III hamsters were painted with $0.5 \%$ DMBA in liquid paraffin three times a week for 14 weeks on their left buccal pouches. Group II hamsters received no further treatment. Group III hamsters received oral administration of ferulic acid at a dose of $40 \mathrm{mg} / \mathrm{kg}$ bw, starting one week before the exposure to the DMBA and continued on days alternate to DMBA painting until one week after the final exposure of the DMBA. Group IV hamsters received oral administration of ferulic acid alone throughout the experimental period. The experiment was terminated at the end of $16^{\text {th }}$ week and all animals were sacrificed by cervical dislocation. Animals were categorized based on their age and body weight. All the animals are inbred, and may not cause difference in results.

\section{IMMUNOHISTOCHEMICAL EXPRESSION OF VEGF}

The antigen that was retrieved from buccal mucosa tissue section was incubated with the respective primary antibody specific to VEGF over night at $4^{0} \mathrm{C}$. The immune complex a subsequently incubated with the secondary antibody conjugated with horseradish peroxidase for 30 minutes at room temperature. The antigen-antibody complex was than detected using 3, 3'-diaminobenzidine, the substrate of horseradish peroxidase. As soon as acceptable color intensity was attained, the slides were counter stained with hematoxylin [27].

\section{COX-2 ACTIVITY BY ELISA}

Buccal mucosa COX-2 activity was assayed colorimetrically by monitoring the appearance of oxidized $\mathrm{N}$, $\mathrm{N}$, N', N'-tetramethyl-P-phenylenediamine (TMPD) at 590nm using ELISA kit for Cyman's COX activity assay kit for COX-2 [28].

\section{EXPRESSION OF NF-אB USING REAL-TIME PCR}

The total RNA was isolated from the buccal mucosa and reverse transcribed to cDNA with random primers (Table 1) using high cDNA. Reverse Transcriptase kit-cDNA was amplified using a thermal cycler to measure the expression pattern of NF- $\kappa \mathrm{B}$, with $\beta$-actin as a control, with SYBRA green fluorophore following the manufacture's recommended amplification procedure. The relative quantification of NF- $\kappa \mathrm{B}$ was measured using threshold cycle (CT) method [29].

\section{STATISTICAL ANALYSIS}

The data is expressed as mean $\pm \mathrm{SD}$. One way analysis of variance (ANOVA) followed by Duncan's Multiple Range Test (DMRT) was used to performed statistical comparison between the groups. The obtained results were considered statistically significant if the $\mathrm{P}$ values were less than 0.05 .

\section{RESULTS}

\section{The Immunoexpression Pattern of Angiogenic Marker}

The VEGF expression pattern of control and experimental hamsters in each group was depicted in Fig. (1). DMBA alone treated hamsters revealed over

Table 1. List of primers used for Real-time PCR.

\begin{tabular}{|c|l|l|}
\hline Genes & Primers & Sequences \\
\hline \hline \multirow{2}{*}{$\beta$-actin } & Forward & 5'-AACCGCGAGAAGATGACCCAGATCATGTTT-3' \\
\cline { 2 - 3 } & Reverse & 5'-AGCAGCCGTGGCCATCTCTTGCTCGAAGTC-3' \\
\hline \multirow{2}{*}{ NF- $\mathrm{kB}$} & Forward & 5'-ATGGACGATCTGTTTCCCCT-3' \\
\cline { 2 - 3 } & Reverse & 5'-CGGTTTACTCGGCAGATCTT-3' \\
\hline
\end{tabular}



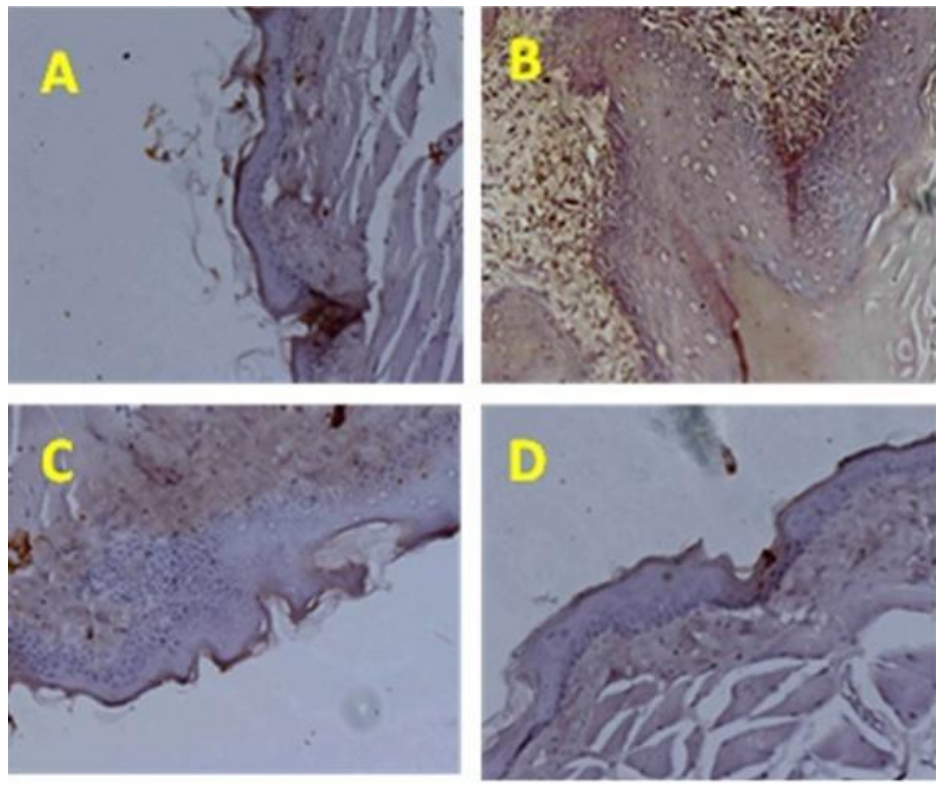

A and D - Control and ferulic acid alone, B - DMBA alone, C- DMBA + ferulic acid.

Fig. (1). Immunoexpression pattern of VEGF protein observed in the buccal mucosa of control and experimental hamsters in each group.

expression of VEGF in their buccal mucosa. Ferulic acid administration to the hamsters treated with DMBA remarkably decreased the expression of VEGF in their buccal mucosa. Ferulic acid alone treated hamsters exhibited expression similar to that of control hamsters.

\section{Activities of COX-2 by Enzyme Linked Immunosorbent Assay [ELISA]}

The status of COX-2 in control and experimental hamaters in each group is shown in Fig (2). COX-2 activity was increased in hamsters treated with DMBA alone. Oral administration of ferulic acid at a dose of $40 \mathrm{mg} / \mathrm{kg}$ bw hamsters treated with DMBA restored the COX-2 activity to near normal range.

\section{Fold Increase in the NF-kB mRNA Expression Pattern Using Real - time PCR}

The primer melting curve and fold increase in the NF- $\kappa \mathrm{B}$ mRNA expression pattern of control and experimental hamsters in each group is depicted in Figs. $(3 \& \mathbf{4})$. Hamsters treated with DMBA alone showed over expression of $\mathrm{NF}-\kappa \mathrm{B}$ mRNA, which was brought back to near normal pattern in DMBA+ ferulic acid treated hamsters. Similar NF- $\kappa$ B mRNA expression pattern was observed in control hamsters and hamsters treated with ferulic acid alone.

\section{DISCUSSION}

In the present study, we noticed upregulation of $\mathrm{NF}-\kappa \mathrm{B}$, COX-2 and VEGF in the buccal mucosa of hamsters treated

\section{COX-2}

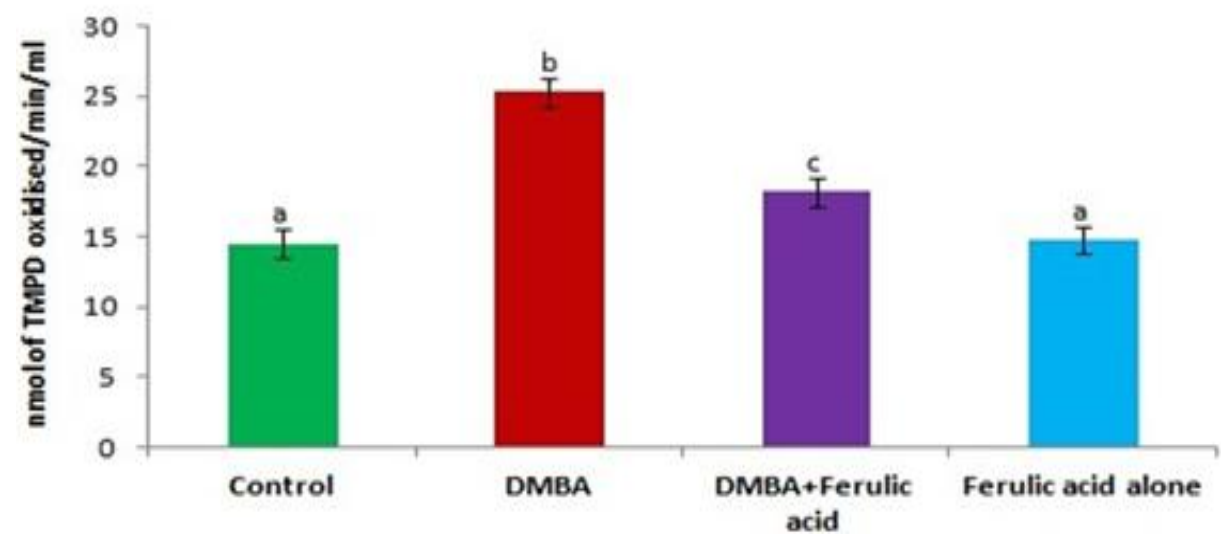

Values are expressed as mean \pm SD for 10 hamsters in each group. Values that do not share a common superscript letter between groups differ significantly at $\mathrm{p}<0.05$. (Analysis of variance followed by DMRT)

Fig. (2). The status of COX-2 in control and experimental hamsters in each group. 


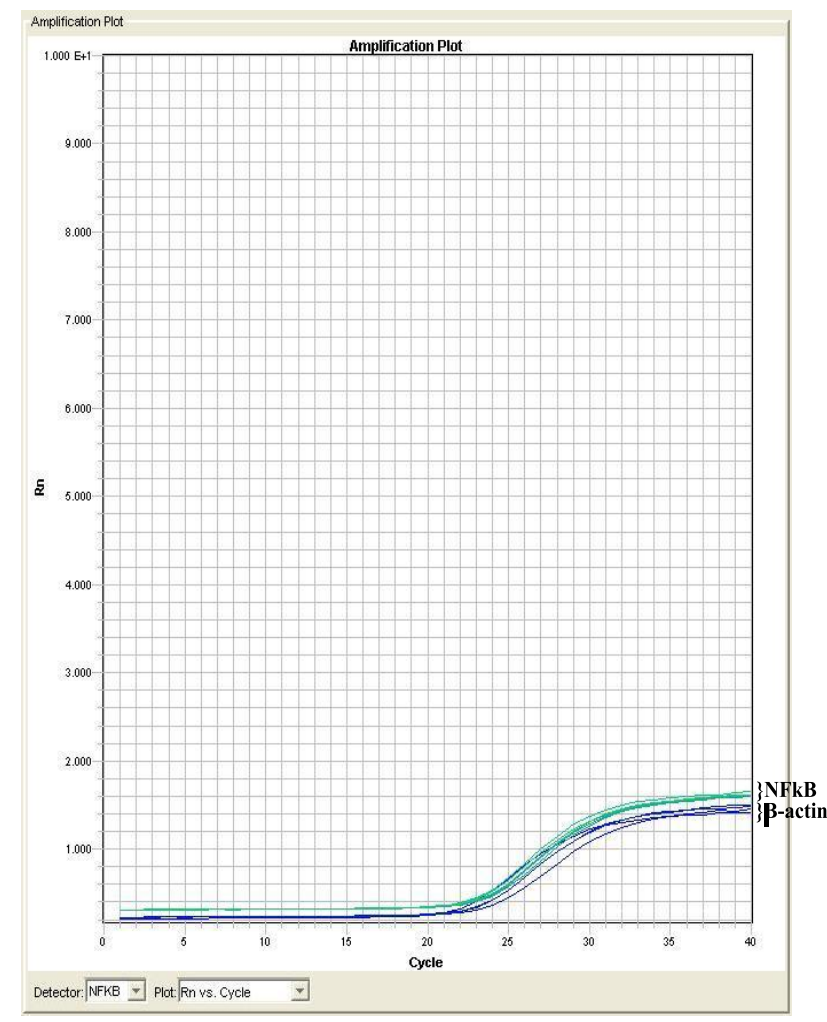

Fig. (3). RT-PCR primers melting curve for $\mathrm{Nf}-\kappa \mathrm{B}$ mRNA expression pattern of control and experimental hamsters in each group.

with DMBA alone. Oral administration of ferulic acid down regulated the above biomarkers in hamsters treated with DMBA. Diverse studies envisaged inflammation as a possible trigger of cancer development. In the present study, we investigated the expression of a panel of biomarkers (VEGF, COX-2, NF-kB) that are associated with carcinogenesis. Mounting evidences also highlighted the significance of inflammation during various stages of carcinogenesis [30, 31]. A large number of studies have utilized NF- $\mathrm{KB}$ and COX-2 as a target for cancer prevention $[32,33]$. Extensive studies pointed out that agents that can able to inhibit the expression of NF- $\mathrm{KB}$ and $\mathrm{COX}-2$ could serve as an anticancer agent [34-36].

$\mathrm{NF}-\kappa \mathrm{B}$ regulates the survival and progression of tumor cell by continuously triggering inflammation. NF- $\mathrm{KB}$ and cyclooxygenase- 2 activity is enhanced by several stimuli that are associated with inflammatory processes [37]. It has been reported that NF- $\kappa B$ inhibits apoptotic pathway by stimulating the expression of BCL-2 and caspases [38]. Upregulation of COX-2 expression is often a common phenomenon during inflammation and carcinogenesis [39]. COX-2 expression is associated with invasion and metastasis in patients with gastric and colon cancer [40, 41]. Over expression of COX-2 is not only associated with tumor progression and metastasis but also involved in tumor angiogenesis [42]. COX-2 maintains cell survival during carcinogenesis by modulating apoptotic proteins. Over expression of COX-2 and NF- $\mathrm{KB}$ were reported in both precancerous and cancerous lesions [43, 44].

Investigation of angiogenic inhibitor could play on important role in cancer therapy and improve clinical outcome. Angiogenesis, a fundamental phenomenon of tumorigenesis, is involved in the progression of tumors and metastasis [45]. Angiogenesis in tumor cells aid for its spread as well as to meet nutrient and oxygen demand for the growth. In recent years, researchers focused their attention to investigate the drugs to inhibit the expression of angiogenic factors, which could provide a valuable therapeutic target for cancer treatment [46, 47]. VEGF, a powerful angiogenic factor, has been implicated in the pathogenesis of neoangiogenesis in various malignancies including oral carcinoma. Over expression of VEGF was reported in epithelial tumors. Mounting evidences pointed out that over

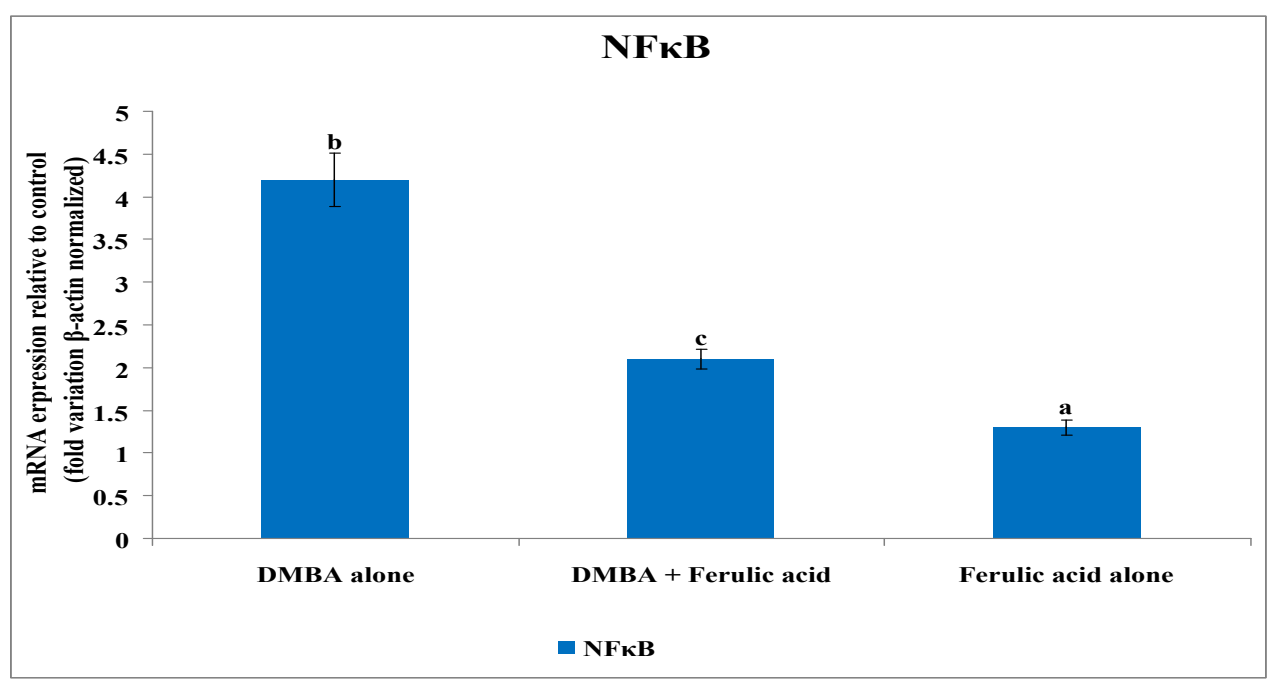

Values are expressed as mean \pm SD for 10 hamsters in each group values that do not share a common superscript letter between groups differ significantly at $\mathrm{p}<0.05$ (DMRT)

Fig. (4). Fold increase in the mRNA expression pattern for NF- $\kappa B$ in hamsters treated with DMBA alone, DMBA + Ferulic acid and Ferulic acid alone. 
expression of VEGF either in circulation or in tumor tissues is associated with poor prognosis as well as tumor progression of several cancers including oral cancer [48-50].

Medicinal plants or their active constituents that possess anti-inflammatory and anti-angiogenic activity could improve the therapeutic outcome in cancer patients. In the present study, ferulic acid administration at a dose of $40 \mathrm{mg} / \mathrm{kg}$ bw down regulated the expression of NF- $\mathrm{\kappa B}$, COX-2 and VEGF in hamsters treated with DMBA. Present results reveal that ferulic acid might have inhibited the inflammatory and angiogenic pathway during DMBA induced oral carcionogenesis. Previous studies from our laboratory demonstrated apoptotic and anticell proliferative potential of ferulic acid during DMBA induced oral carcinogenesis. Down regulation of NF- $\mathrm{KB}$ and $\mathrm{COX}-2$ observed in the DMBA+ ferulic acid treated animals suggested that NF- $\mathrm{KB}$ and COX-2 inhibition might have enhanced the apoptotic potential of ferulic acid during oral carcinogenesis. Ferulic acid also prevented tumorigenesis in several types of experimental carcinogenesis including oral cancer.

Islam et al. [51] reported that phytosteryl ferulate significantly inhibited the expression of NF- $\mathrm{KB}$ in LPS stimulated RAW 264.7 macrophages. Jung et al., [52] suggested that dietary ferulic acid suppressed NF- $\mathrm{\kappa B}$ activity through inhibition of NIK/IKK and MAPK in vivo. It has been reported that ferulic acid augmented angiogenesis via VEGF, PDGF and HIF-1 $\alpha$ in human umbilical vein endothelial cells $[53,54]$. In contrast, we noticed a down regulation of VEGF in DMBA + ferulic acid treated animals. This is probably due to suppression of NF- $\mathrm{KB}$ and Cyclin D1 by ferulic acid during DMBA induced oral carcinogenesis. Srivastava et al [55, 56] explored glutathione peroxidase, glutathione-S-transferase and glutathione reductase as a major biomarkers in the diagnosis as well as therapeutics of oral cancer.

Our present study concludes that the anti-inflammatory and anti-angiogenic effect of ferulic acid might have served as an important phenomenon in the suppression of or delayed the formation of oral tumors in the buccal mucosa of hamsters treated with DMBA.

\section{Limitation of the Study}

In the present study, we have not measured the ferulic acid content in the blood of experimental animals along with the parameters related to inflammation, and angiogenesis.

\section{Future Direction}

The results of the present study highlight the significance of ferulic acid in therapeutic intervention methodology against oral carcinogenesis in which angiogenesis and inflammation play a key role. The present study may thus warrant to consider ferulic acid as a promising candidature for oral cancer treatment along with currently available therapeutic drugs. Efforts will therefore be taken up to explore the anti-inflammatory anti-angiogenic potential of ferulic acid in human carcinogenesis.

\section{CONFLICT OF INTEREST}

The authors confirm that this article content has no conflict of interest.

\section{ACKNOWLEDGEMENTS}

Financial support from University Grants Commission, New Delhi is gratefully acknowledged.

\section{REFERENCES}

[1] Gupta B, Ariyawardana A, Johnson NW. Oral cancer in India continues in epidemic proportions: evidence base and policy initiatives. Int Dent J 2013; 63: 12-25.

[2] Radoi L, Luce D. A review of risk factors for oral cavity cancer: the importance of a standardized case definition. Community Dent Oral Epidemiol 2013; 41(2); 97-109.

[3] Gomez I, Warnakulasuriya S, Varela-Centelles PI, et al. Is early diagnosis of oral cancer a feasible objective? Who is to blame for diagnostic delay? Oral Dis 2010; 16: 333-42.

[4] Williams HK. Molecular pathogenesis of oral squamous carcinoma. Mol Path 2000; 53: 165-72.

[5] Harris RE. Cyclooxygenase-2 (COX-2) and the inflammogenesis of cancer. Subcell Biochem 2007; 42: 93-126.

[6] Cheng J, Fan XM. Role of cyclooxygenase-2 in gastric cancer development and progression. World J Gastroenterol 2013; 19: 7361-68.

[7] DiDonato JA, Mercurio F, Karin M. NF- $\kappa B$ and the link between inflammation and cancer. Immunol Rev 2012; 246: 379-400.

[8] Kourelis K, Sotiropoulou-Bonikou G, Vandoros G, Repanti M, Varakis I, Goumas P. Coordinated upregulation of COX-2 and NFkappaB is a steady feature of laryngeal carcinogenesis. ORL J Otorhinolaryngol Relat Spec 2007; 69: 181-9.

[9] Charalambous MP, Lightfoot T, Speirs V, Horgan K, Gooderham NJ. Expression of COX-2, NF-kappaB-p65, NF-kappaB-p50 and IKKalpha in malignant and adjacent normal human colorectal tissue. Br J Cancer 2009; 101: 106-115.

[10] Sawhney M, Rohatgi N, Kaur J, et al. Expression of NF-kappaB parallels COX-2 expression in oral precancer and cancer: association with smokeless tobacco. Int J Cancer 2007; 120: 2545 56.

[11] Holopainen T, Bry M, Alitalo K, Saaristo A. Perspectives on lymphangiogenesis and angiogenesis in cancer. J Surg Oncol 2011; 103: 484-8.

[12] Carmeliet P. VEGF as a key mediator of angiogenesis in cancer. Oncology 2005; 69: 4-10.

[13] Johnson KE, Wilgus TA. Multiple roles for VEGF in nonmelanoma skin cancer: angiogenesis and beyond. J Skin Cancer 2012; 2012: 483439.

[14] Ravikumar G, Crasta JA. Vascular endothelial growth factor expression in ovarian serous carcinomas and its effect on tumor proliferation. South Asian J Cancer 2013; 2: 87-90.

[15] Kim JW, Koh Y, Kim DW, et al. Clinical Implications of VEGF, TGF- $\beta 1$, and IL- $1 \beta$ in Patients with advanced non-small cell lung cancer. Cancer Res Treat 2013; 45: 325-33.

[16] dos Santos Almeida A, Oliveira DT, Pereira MC, et al. Podoplanin and VEGF-C immunoexpression in oral squamous cell carcinomas: prognostic significance. Anticancer Res 2013; 33: 3969-76.

[17] Onn A, Bar J, Herbst RS. Angiogenesis inhibition and lung-cancer therapy. Lancet Oncol 2014; 15: 124-35.

[18] Zhao Z, Moghadasian MH. Chemistry, natural sources, dietary intake and pharmacokinetic properties of ferulic acid: a review. Food Chem 2008; 10: 691-702.

[19] Anselmi C, Centini M, Andreassi M, et al. Conformational analysis: a tool for the elucidation of the antioxidant properties of ferulic acid derivatives in membrane models. J Pharm Biomed Anal 2004; 35: 1241-49.

[20] Rukkumani R, Aruna K, Varma PS, Menon VP. Influence of ferulic acid on circulatory prooxidant anti-oxidant status during alcohol and PUFA induced toxicity. J Physiol Pharmacol 2004; 55: 551-61.

[21] Balakrishnan S, Menon VP, Manoharan S, Rajalingam K. Antigenotoxic effect of ferulic acid in 7,12- 
dimethylbenz[a]anthracene-induced genotoxicity. Afr J Tradit Complement Altern Med 2007; 5: 32-8.

[22] Alias LM, Manoharan S, Vellaichamy L, Balakrishnan S, Ramachandran CR. Protective effect of ferulic acid on 7,12dimethylbenz[a]anthracene-induced skin carcinogenesis in Swiss albino mice. Exp Toxicol Pathol 2009; 61: 205-14.

[23] Baskaran N, Manoharan S, Balakrishnan S, Pugalendhi P. Chemopreventive potential of ferulic acid in 7,12dimethylbenz[a]anthracene-induced mammary carcinogenesis in Sprague-Dawley rats. Eur J Pharmacol 2010; 637: 22-9.

[24] Balakrishnan S, Menon VP, Manoharan S. Ferulic acid inhibits 7,12-dimethylbenz[a]anthracene-induced hamster buccal pouch carcinogenesis. J Med Food 2008; 11: 693-700.

[25] Prabhakar MM, Manoharan S, Karthikeyan S, et al. Proapoptotic potential of ferulic acid during 7,12- dimethyl benz(a)anthracene induced hamster buccal pouch carcinogenesis. Int J Res Pharm Sci 2012; 3: 622-7.

[26] Prabhakar MM, Vasudevan K, Karthikeyan S, Baskaran N, Silvan S, Manoharan S. Anti-cell proliferative efficacy of ferulic acid against 7, 12-dimethylbenz(a) anthracene induced hamster buccal pouch carcinogenesis. Asian Pac J Cancer Prev 2012; 13: 5207-11.

[27] Nakagawa K, Yamamura K, Maeda S. Expression in epidermal keratinocytic diseases. Cancer 1994; 74: 1720-4.

[28] Manoharan S, Sindhu G, Nirmal MR, Vetrichelvi V, Balakrishnan S. Productive effect of Berberine on expression pattern of apoptotic, cell proliferative, inflammatory and angiogenic markers during 7,12-dimethylbenz(a) anthracene induced hamster buccal pouch carcinogenesis. Pak J Biol Sci 2011; 14; 918-32.

[29] Vinothkumar V, Manoharan S, Sindhu G, Nirmal MR, Vetrichelvi V. Geraniol modulates cell proliferation, apoptosis, inflammation, and angiogenesis during 7,12-dimethylbenz[a]anthracene-induced hamster buccal pouch carcinogenesis. Mol cell Biochem 2012; 369: 17-25.

[30] Maher SG, Reynolds JV. Basic concepts of inflammation and its role in carcinogenesis. Recent Results Cancer Res 2011; 185: 1-34.

[31] Piva MR, DE Souza LB, Martins-Filho PR, Soares RC, DE Santana Santos T, DE Souza Andrade ES. Role of inflammation in oral carcinogenesis (Part I):Histological grading of malignancy using a binary system. Oncol Lett 2011; 2: 1225-31.

[32] Son PS, Park SA, Na HK, Jue DM, Kim S, Surh YJ. Piceatannol, a catechol-type polyphenol, inhibits phorbol ester-induced NF\{kappa\}B activation and cyclooxygenase- 2 expression in human breast epithelial cells: cysteine 179 of IKK \{beta\} as a potential target. Carcinogenesis 2010; 31: 1442-49.

[33] Piplani H, Vaish V, Sanyal SN. Dolastatin 15, a mollusk linear peptide, and Celecoxib, a selective cyclooxygenase-2 inhibitor, prevent preneoplastic colonic lesions and induce apoptosis through inhibition of the regulatory transcription factor NF- $\mathrm{KB}$ and an inflammatory protein, iNOS. Eur J Cancer Prev 2012; 21: 511-22.

[34] Luqman S, Pezzuto JM. NFkappaB: a promising target for natural products in cancer chemoprevention. Phytother Res 2010; 24: 94963.

[35] Moreira L1, Castells A. Cyclooxygenase as a target for colorectal cancer chemoprevention. Curr Drug Targets 2011; 12: 1888-94.

[36] Ghosh N, Chaki R, Mandal V, Mandal SC. COX-2 as a target for cancer chemotherapy. Pharmacol Rep 2010; 62: 233-44.

[37] Nah SS, Won HJ, Ha E, et al. Epidermal growth factor increases prostaglandin E2 production via ERK1/2 MAPK and NF-kappaB pathway in fibroblast like synoviocytes from patients with rheumatoid arthritis. Rheumatol Int 2010; 30: 443-9.

[38] Pratheeshkumar P, Thejass P, Kutan G. Diallyl disulfide induces caspase-dependent apoptosis via mitochondria-mediated intrinsic pathway in B16F-10 melanoma cells by up-regulating p53, caspase-3 and down-regulating pro-inflammatory cytokines and nuclear factor- $\kappa \beta$-mediated Bcl-2 activation. J Environ Pathol Toxicol Oncol 2010; 29: 113-25.

[39] Wun T, McKnight H, Tuscano JM. Increased cyclooxygenase-2 (COX-2): a potential role in the pathogenesis of lymphoma. Leuk Res 2004; 28: 179-90.

[40] Koga T, Shibahara K, Kabashima A, et al. Overexpression of cyclooxygenase-2 and tumor angiogenesis in human gastric cancer. Hepatogastroenterology 2004; 51: 1626-30.

[41] Lim SJ, Lee SH, Joo SH, Song JY, Choi SI. Cytoplasmic expression of HuR is related to cyclooxygenase-2 expression in colon cancer. Cancer Res Treat 2009; 41: 87-92.

[42] Agarwal S, Reddy GV, Reddanna P. Eicosanoids in inflammation and cancer: the role of COX-2. Expert Rev Clin Immunol 2009; 5: $145-65$.

[43] Wu WK, Sung JJ, Lee CW, Yu J, Cho CH. Cyclooxygenase-2 in tumorigenesis of gastrointestinal cancers: an update on the molecular mechanisms. Cancer Lett 2010; 295: 7-16.

[44] Zhang H, Sun XF. Overexpression of cyclooxygenase-2 correlates with advanced stages of colorectal cancer. Am J Gastroenterol 2002; 97: 1037-41.

[45] Fens MH, Storm G, Schiffelers RM. Tumor vasculature as target for therapeutic intervention. Expert Opin Investig Drugs 2010; 19: $1321-38$

[46] Pinto A, Redondo A, Zamora P, Castelo B, Espinosa E. Angiogenesis as a therapeutic target in urothelial carcinoma. Anticancer Drugs 2010; 21: 890-6.

[47] El-Kenawi AE, El-Remessy AB. Angiogenesis inhibitors in cancer therapy: mechanistic perspective on classification and treatment rationales. Br J Pharmacol 2013; 170: 712-9.

[48] Wang D, Luo L, Chen W, et al. Significance of the vascular endothelial growth factor and the macrophage migration inhibitory factor in the progression of hepatocellular carcinoma. Oncol Rep 2014; 31: 1199-204.

[49] Lu JJ, Ma J, Miao R, Gu Y, Zhong FT. Expression of vascular endothelial growth factor D in human esophageal squamous cell carcinoma tissue and its significance. Zhonghua Wei Chang Wai Ke Za Zhi 2013; 16(12): 1191-4.

[50] Silvan S, Manoharan S. Apigenin prevents deregulation in the expression pattern of cell-proliferative, apoptotic, inflammatory and angiogenic markers during 7,12-dimethylbenz[a]anthraceneinduced hamster buccal pouch carcinogenesis. Arch Oral Biol 2013; 58: 94-101.

[51] Islam MS, Yoshida H, Matsuki N, et al. Antioxidant, Free RadicalScavenging, and NF-KB-Inhibitory Activities of Phytosteryl Ferulates: Structure- Activity Studies. J Pharmacol Sci 2009; 111: 328-37.

[52] Jung KJ, Go EK, Kim JY, Yu BP, Chung HY. Supperssion of agereleated renal changes in NF- $\mathrm{kB}$ and its target gene experession by dietary ferulate. J Nutr Biochem 2009; 20: 388 .

[53] Lin CM, Chiu JH, Wu IH, Wang BW, Pan CM, Chen YH. Ferulic acid augments angiogenesis via VEGF, PDGF and HIF-1 alpha. J Nutr Biochem 2010; 21: 627-33.

[54] Wang J, Yuan Z, Zhao H, et al. Ferulic acid promotes cells proliferation through up-regulating cyclin D1 and VEGF. J Ethnopharmacol 2011; 137: 992-7.

[55] Sirastava R., Sharama R, Singh RB, Wilson DW, Mishra S. Computational studies and molecular dynamics of the potent biochemical and molecular markers in relevance to oral cancer. Open Nutraceuticals J 2012; 5: 213-8.

[56] 56. Sirastava R, Sharama R, Mishara S, Singh RB. Biochemical and molecular biological studies on oral cancer: An overview. Open Nutraceuticals J 2011; 4: 180-8.

(C) Manoharan et al.; Licensee Bentham Open.

This is an open access article licensed under the terms of the Creative Commons Attribution Non-Commercial License (http://creativecommons.org/licenses/ by-nc/3.0/) which permits unrestricted, non-commercial use, distribution and reproduction in any medium, provided the work is properly cited. 